\title{
Effects of Surface Working on the Structures of Oxide Films by Wet Oxidation in Austenitic Stainless Steels*
}

\author{
By Tadayuki Nakayama** and Yoshiki Oshida***
}

\begin{abstract}
Effects of the stability of austenitic phases worked by shot-peening on the structures and chemical compositions of oxide films formed on 18-8 and 18-18 stainless steels by wet oxidation have been studied mainly by electron diffraction and characteristic X-ray micro-analysis.

The following results are obtained by the present investigation.

The oxide films formed on the surfaces of 18-8 stainless steels worked by shot-peening after mechanical or chemical polishing by oxidizing in high-temperature $\left(300^{\circ} \mathrm{C}\right)$ water for $1 \mathrm{hr}$ were the same in structure and chemical composition for both polished surfaces. The oxides were identical with the corundum type oxides consisting of $(\mathrm{Cr}, \mathrm{Fe}\rangle_{2} \mathrm{O}_{3}$ possibly accompanied by $\alpha-\mathrm{Fe}_{2} \mathrm{O}_{3}$, showing characteristic X-rays of $\mathrm{Fe}$ and $\mathrm{Cr}$.

On the contrary, the surface of the 18-18 stainless steel worked by shot-peening was covered with an oxide film which gave diffraction patterns showing clearly the existence of spinel type oxides with corundum type oxides of weak intensity under the same oxidizing conditions as in the case of 18-8 stainless steel. Further, besides $\mathrm{Fe}$ and $\mathrm{Cr}, \mathrm{Ni}$ was detected from this oxide film. And the residual strain introduced by the shot-peening did not affect the structures and compositions of the wet oxidized films. From the above, it becomes clear that the stability of austenitic phases affects the structures of oxide films formed by wet oxidation of $\mathrm{Fe}-\mathrm{C}$ r- $\mathrm{Ni}$ austenitic stainless steels.
\end{abstract}

(Received January 30, 1971)

\section{Introduction}

The present authors have previously studied the effects of surface polishing conditions on the structures of oxide films formed on the surfaces of 18-8 stainless steels during the initial oxidation in high temperature water $\left(300^{\circ} \mathrm{C}, 1 \mathrm{hr}\right)$ and reported that the corundum type oxides containing $\mathrm{Fe}$ and $\mathrm{Cr}$ were formed on the mechanically polished surfaces, and the spinel type oxides containing $\mathrm{Ni}$ besides $\mathrm{Fe}$ and $\mathrm{Cr}$ were produced on the chemically or electrolytically polished surfaces ${ }^{(1)}$.

In the present investigation, shot-peening which is a surface working method was performed on the surfaces of austenitic 18-8 and 18-18 stainless steels and the effects of the resulting residual strain layers introduced by the shot-peening were studied on the structures and chemical constitutions of oxide films formed on these alloys in high temperature water.

\section{Experimental Procedure}

Austenitic stainless steels, whose chemical compositions are shown in Table 1, were cold-rolled sheets with a thickness of $1 \mathrm{~mm}$, and after being solution-treated at $1050^{\circ} \mathrm{C}$, they were cut into pieces with dimensions of $20 \times 100 \mathrm{~mm}$ for the shot-peening and were polished mechanically with the emery paper of grit 500. Specimens of 18-8 stainless steel, which is noted for its easy martensitic transformation by mechanical polishing ${ }^{(2)}$, were mechanically polished with emery paper and then chemically polished by etching in a $\mathrm{H}_{2} \mathrm{O}_{2}-\mathrm{HCl}-\mathrm{HF}(2$ : 1 : 1 by vol.) solution for $1 \mathrm{~min}$ in order to remove the surface worked layer. The specimens of 18-8 stainless steel after mechanical or chemical polishing and of stable austenitic 18-18 stainless steel after mechanical polishing were degreased and cleaned with $\mathrm{C}_{6} \mathrm{H}_{6},\left(\mathrm{CH}_{3}\right)_{2} \mathrm{CO}$, $\mathrm{CH}_{3} \mathrm{OH}$ and $\mathrm{C}_{2} \mathrm{H}_{5} \mathrm{OH}_{5}$, and worked by shot-peening under the conditions shown in Table 2. These specimens were again degreased and cleaned in $\mathrm{CH}_{3} \mathrm{OH}$ prior to oxidation.

The oxidation was done by heating the specimens in aerated deionized water $(\mathrm{pH}: 6.8$, dissolved oxygen conc. : $\leq 0.8 \mathrm{ppm}$ ) sealed in an 18-8 stainless steel autoclave at $300^{\circ} \mathrm{C}$ for $1 \mathrm{hr}$.

The surfaces of all specimens, covered with tempercolored thin oxide films, were scratched by a sharp-edged knife in a checkered way. The oxide films were stripped from the substrata after immersing them into a $\mathrm{Br}_{2}-$ $\mathrm{CH}_{3} \mathrm{OH}(1: 200$ by vol.) reagent at room temperature for $5 \sim 10 \mathrm{hr}$.

The stripped each oxide film was cleaned in $\mathrm{CH}_{3} \mathrm{OH}$

Table 1 Chemical compositions of materials (wt $\%$ )

\begin{tabular}{c|c|c|c|c|c|c|c|c|c}
\hline & $\mathrm{C}$ & $\mathrm{Si}$ & $\mathrm{Mn}$ & $\mathrm{P}$ & $\mathrm{S}$ & $\mathrm{Ni}$ & $\mathrm{Cr}$ & $\mathrm{Mo}$ \\
\hline $18-8$ stainless steel & 0.06 & 0.81 & 1.66 & 0.035 & 0.011 & 9.10 & 18.42 & 0.30 \\
\hline 18 -18 stainless steel & 0.074 & 0.32 & 1.55 & 0.010 & 0.012 & 20.09 & 16.99 & - \\
\hline
\end{tabular}

* This paper was published in J. Japan Inst. Metals, in Japanese $34(1970), 1264$.

** Department of Metallurgical Engineering, Faculty of Science and Engineering, Waseda University, Tokyo, Japan.
Yokohama Ship Ward and Engine Works, Mitsubishi Heavy Industry, Ltd., Yokohama, Japan.

(1) T. Nakayama and Y. Oshida : Trans. JIM, 11 (1970), 245.

(2) S. Yamaguchi : Z. Phys., 140 (1955), 577.

Trans. J I M

1971 Vol. 12 
Table 2 Conditions for shot-peening

$\begin{array}{ll}\text { Shot } & : 0.5 \mathrm{~mm} \mathrm{18-8} \text { stainless steel shot } 100 \mathrm{~g} \\ \text { Drum speed } & : 5000 \mathrm{rpm} \\ \text { Attack cycle } & : 20 \text { cycles } \\ \text { Coverage } & : 100 \% \\ \text { Arc height } & : 0.26 \mathrm{mmA}\end{array}$

and mounted on a cupper mesh. These oxide films were observed with the Hitachi HU-11D electron microscope, and microanalyzed under the HXA-1 X-ray microanalyzer (spectro-crystal : mica) attached to the electron microscope on the exactly same area of each specimen as that for electron diffraction and microscopy. The acceleration voltage was $100 \mathrm{kV}$, and reduced to $25 \mathrm{kV}$ for $\mathrm{X}$-ray microanalysis using a beam diameter of ca. $4 \mu$.

\section{Experimental Results and Discussions}

\section{18-8 stainless steel}

The oxide film formed on the surface of 18-8 stainless steel worked by the shot-peening after mechanical polishing in high temperature water showed similar structures and chemical compositions to those of the oxide film formed on chemical polishing as a pretreatment prior to the shot-peening. An example of the electron micrographs of the oxide films is shown in Photo. 1 , in which the oxide film was thickened to some extent at the impact point by shots. A transmission electron diffraction pattern of the oxide film is shown in Photo. 2 as an example and identified as the corundum type diffraction lines. From a precise analysis of the lattice spacings from these diffraction lines (Table 3) it was clarified that the oxide film was identical with the $\alpha-\mathrm{Fe}_{2} \mathrm{O}_{3}$ or $(\mathrm{Cr}, \mathrm{Fe})_{2} \mathrm{O}_{3}$ crystal. From the characteristic $\mathrm{X}$-ray spectrum of this oxide film which shows the existence of $\mathrm{Cr}$ besides $\mathrm{Fe}$, it became evident that the oxide film consisted of $(\mathrm{Cr}, \mathrm{Fe})_{2} \mathrm{O}_{3}$ alone or coexisted with $\alpha-\mathrm{Fe}_{2} \mathrm{O}_{3}$ (Fig. 1).

The structure of the wet oxide film produeed on the chemically polished surface of this alloy under the same heating conditions consisted of the spinel type oxide containing $\mathrm{Ni}$ besides $\mathrm{Fe}$ and $\mathrm{Cr}$, as previously reported by

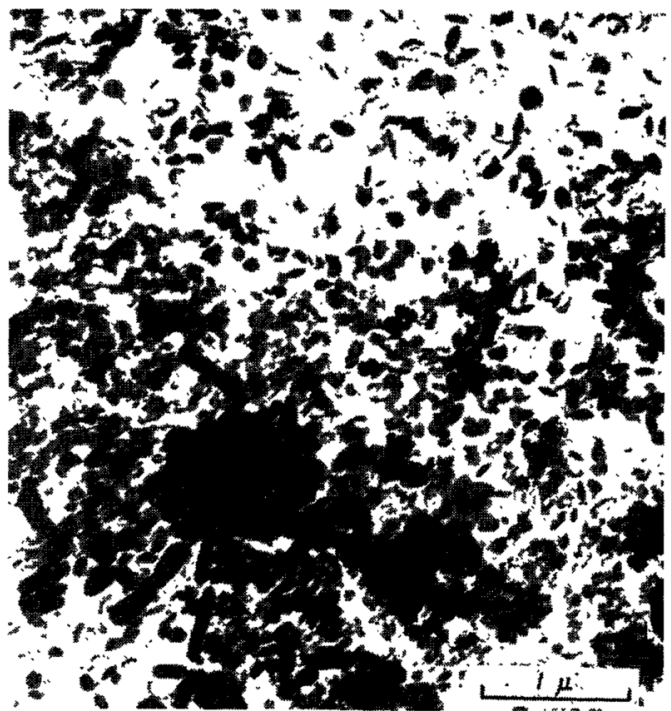

Photo. 1 Electron micrograph of the oxide film formed on the mechanically pslished surface of 18-8 stainless steel worked by shot-peening in high temperature water at $300^{\circ} \mathrm{C}$ for $1 \mathrm{hr}$.

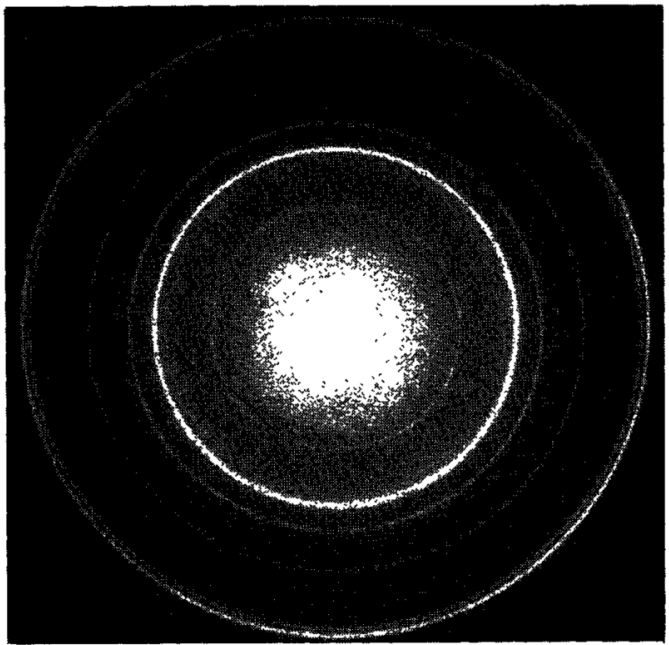

Photo. 2 Electron diffractogram of the corundum type oxide film formed on the mechanically polished surface of 18-8 stainless steel worked by shot-peening in high temperature water at $300^{\circ} \mathrm{C}$ for $1 \mathrm{hr}$.

Table 3 Lattice spacings of the oxide films formed on the mechanically polished surface of 18-8 stainless steel worked by shot-peening in high temperature water at $300^{\circ} \mathrm{C}$ for $1 \mathrm{hr}$

\begin{tabular}{|c|c|c|c|c|c|c|c|}
\hline \multicolumn{2}{|c|}{ Corundum type oxide } & \multicolumn{2}{|c|}{$\alpha-\mathrm{Fe}_{2} \mathrm{O}_{3}{ }^{(\mathrm{a})}$} & \multicolumn{2}{|c|}{$(\mathrm{Cr}, \mathrm{Fe})_{2} \mathrm{O}_{3}{ }^{(\mathrm{b})}$} & \multicolumn{2}{|c|}{$\mathrm{Cr}_{2} \mathrm{O}_{3}{ }^{(\mathrm{c})}$} \\
\hline$d_{\text {obs. }}(\AA)$ & $I_{\text {obs }}$ & $d(\AA)$ & $I / I_{1}$ & $d(\AA)$ & $I / I_{1}$ & $d(\AA)$ & $I / I_{1}$ \\
\hline $\begin{array}{l}3.68 \\
2.69 \\
2.51 \\
2.21 \\
2.07 \\
1.84 \\
1.69 \\
1.64 \\
1.60 \\
1.48 \\
1.45\end{array}$ & $\begin{array}{c}\text { m. st. } \\
\text { v. w. } \\
\text { v. st. } \\
\text { st. } \\
\text { w. } \\
\text { m. st. } \\
\text { w. } \\
\text { v. w. } \\
\text { v. w. } \\
\text { m. st. } \\
\text { st. }\end{array}$ & $\begin{array}{l}3.68 \\
2.69 \\
2.51 \\
2.20 \\
2.07 \\
1.837 \\
1.691 \\
1.634 \\
1.596 \\
1.484 \\
1.451\end{array}$ & $\begin{array}{r}70 \\
100 \\
80 \\
70 \\
10 \\
70 \\
80 \\
10 \\
40 \\
70 \\
80\end{array}$ & $\begin{array}{l}3.68 \\
2.69 \\
2.51 \\
2.19 \\
2.06 \\
1.83 \\
1.68 \\
\overline{1.59} \\
1.47 \\
1.44\end{array}$ & $\begin{array}{r}80 \\
80 \\
80 \\
80 \\
20 \\
80 \\
100 \\
- \\
20 \\
80 \\
90\end{array}$ & $\begin{array}{l}3.633 \\
2.666 \\
2.480 \\
2.176 \\
2.048 \\
1.8156 \\
1.672 \\
-\overline{1.59} \\
1.465 \\
1.4314\end{array}$ & $\begin{array}{r}74 \\
100 \\
96 \\
38 \\
9 \\
39 \\
90 \\
13 \\
25 \\
40\end{array}$ \\
\hline
\end{tabular}

(a) A.S. T. M. X-ray powder data card, No. 6-0502

(b) A.S. T. M.X-ray powder data card, No. 2-1357

(c) A.S.T.M. X-ray powder data card, No. 6-0504 


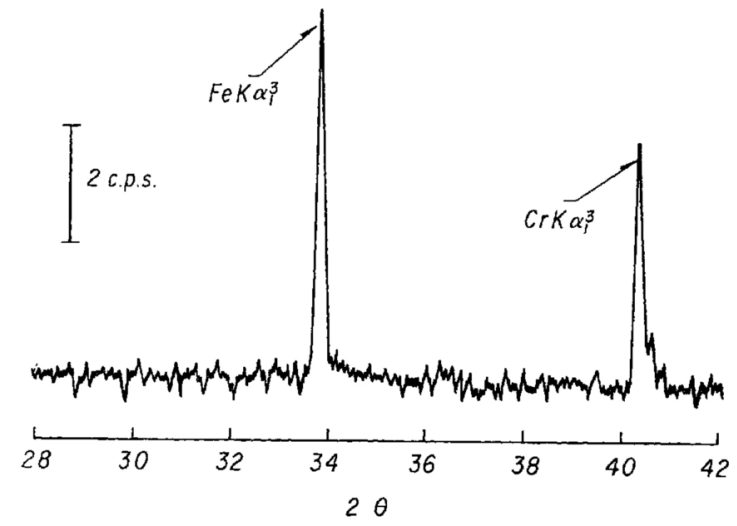

Fig. 1 Characteristic X-ray spectrum obtained from the oxide film produced on the mechanically polished surface of 18-8 stainless steel worked by shot-peening after heating in water at $300^{\circ} \mathrm{C}$ for $1 \mathrm{hr}$.

the present authors ${ }^{(1)}$. However, it was an interesting to note that the surface worked by the shot-peening after chemical polishing was covered with the corundum type oxide consisting of $\mathrm{Fe}$ and $\mathrm{Cr}$ in the same way as in the case of mechanical polishing as a pre-treatment.

The reason for the difference in the structures and chemical compositions between the oxide films formed on the mechanically worked surface and the chemically polished surface still remains unsolved, however, it may be ascribed in part to the so-called strain-induced transformation of the surface layer of the present alloy.

\section{18-18 stainless steel}

As described above, after shot-peening, a corundum type oxide having $\mathrm{Fe}$ and $\mathrm{Cr}$ was formed on the surface of an 18-8. stainless: steel in which the strain-induced transformation to the martensitic phase was caused by surface working.

Then an attempt was made to examine the effect of the same shot-peening on the structure of oxide films produced on the surface of a stable austenitic 18-18 stainless steel containing a large amount of $\mathrm{Ni}$. The transmission electron diffraction pattern of the oxide film showed the diffraction lines of the spinel type oxide of strong intensity along with the corundum type oxide of weak intensity (Photo. 3), and the characteristic $\mathrm{X}$-ray spectrum of the oxide film showed clearly the existence of $\mathrm{Ni}$ besides $\mathrm{Fe}$ and $\mathrm{Cr}$ (Fig. 2). These findings suggested that $\mathrm{Ni}$ was contained in the spinel type oxide. Furthermore, this spinel type oxide was not changed to the corundum type oxide but remained itself even after being heated in air at $1000^{\circ} \mathrm{C}$ for $3 \mathrm{hr}$ on a Pt mesh (Photo. 4). From this result it was clear that $\mathrm{Ni}$ was contained in the spinel type oxide and contributed to the stability of the oxide film.

The unstable austenitic 18-8 stainless steel was transformed to the martensitic phase by shot-peening and the corundum type oxide having $\mathrm{Fe}$ and $\mathrm{Cr}$ was formed on the surface during the wet oxidation. On the other hand, the stable austenitic18-18 stainless steel containing a larger amount of $\mathrm{Ni}$ as an alloying element retained a stable austenitic phase even after the surface was changed by shot-peening to the strain-worked layer and

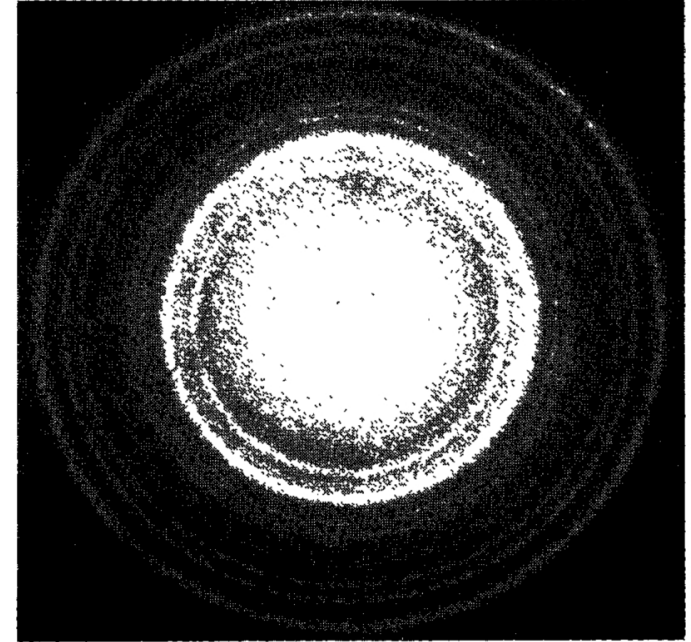

Photo. 3 Electron diffractogram of the spinel type oxide film formed on the mechanically polished surface of 18-18 stainless steel worked by shot-peening in high temperature water at $300^{\circ} \mathrm{Ci}$ for $1 \mathrm{hr}$.

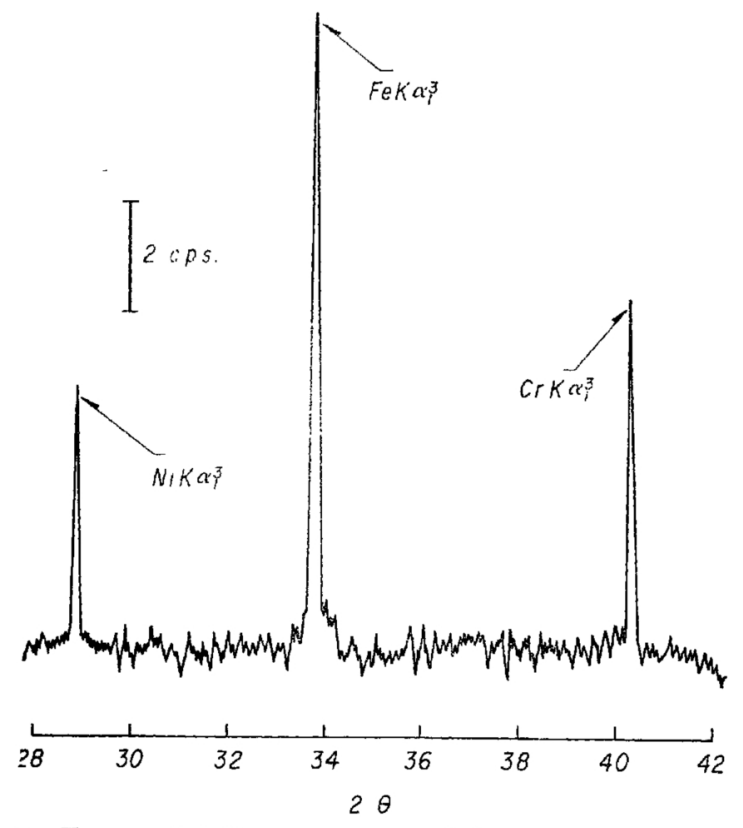

Fig. 2 Characteristic X-ray spectrum of the oxide film produced on the mechanically polished surface of 18-18 stainless steel worked by shot-peening after heating in water at $300^{\circ} \mathrm{C}$ for $1 \mathrm{hr}$.

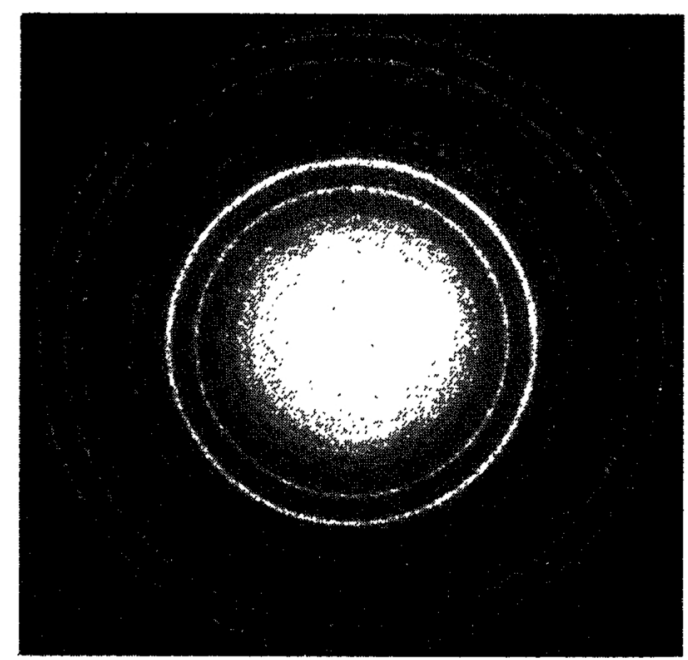

Photo. 4 Electron diffractogram of the spinel type oxide film after heating the same oxide film shown in Photo. 3 in air at $1000^{\circ} \mathrm{C}$ for $3 \mathrm{hr}$. 
a different structure of the oxide film from that of 18-8 stainless steel was formed on the surface. Besides, it became clear that $\mathrm{Ni}$ contributed greatly to the formation of the spinel type oxide, as already reported ${ }^{(1)(3)}$.

\section{Conclusions}

The surfaces of austenitic 18-8 and 18-18 stainless steels were worked by shot-peening and were made contact with high temperature water, and the effects of the stability of the austenitic phase on the structures and chemical compositions of the oxide films were examined mainly by means of transmission electron diffraction and $\mathrm{X}$-ray microanalysis.

After the strain-induced transformed phase was formed on the surface layer by shot-peening on the mechanically and chemically polished surfaces of 18-8 stainless steel, the oxide films produced on these surfaces during the oxidation in high temperature water $\left(300^{\circ} \mathrm{C}\right.$, $\mathrm{lhr}$ ) gave the same results in their structures and chemical compositions and were identical with $(\mathrm{Cr}, \mathrm{Fe})_{2} \mathrm{O}_{3}$ possibly accompanied by $\alpha-\mathrm{Fe}_{2} \mathrm{O}_{3}$. These oxides were in higher order than the spinel type oxides formed on

(3) T. Nakayama and Y. Oshida : Corrosion, 24 (1968), No. 10, 336. the chemically or electrolytically polished surface under the same heating conditions.

In the case of the stable austenitic 18-18 stainless steel containing a large amount of $\mathrm{Ni}$, the oxide film produced on the surface worked by shot-peening in high temperature water gave the diffraction lines showing the existence of the clear spinel type oxide with faint corundum type oxide. Moreover, besides $\mathrm{Fe}$ ane $\mathrm{Cr}, \mathrm{Ni}$ was detected from the oxide film. In the case of 18-18 stainless steel, which held a stable austenitic phase even after the residual strain layer was produced during the shot-peening, it-became clear that the effects of the surface working such as the formation of a higher order oxide of the corundum type were not recognized.

From the above considerations, the stability of the austenitic phase seems to contribute to the structures of the oxide films formed on stainless steels of the $\mathrm{Fe}-\mathrm{Cr}-$ $\mathrm{Ni}$ system during the wet oxidation.

\section{Acknowledgment}

The authors express their appreciation to Professor M. Hirose, Faculty of Science and Engineering of Waseda University, for his valuable suggestions and cooperation throughout the experimental work. 